\title{
Boards in action: processes and practices of 'strategising' in the Boardroom
}

\section{Cate Watson $^{1}$ (D) $\cdot$ Aileen Ireland ${ }^{1}$ (D)}

Accepted: 29 October 2020 / Published online: 12 December 2020

(C) The Author(s) 2020

\begin{abstract}
Normative expectations are that Governing Boards will be involved in setting the strategic direction of the organisation. However, knowledge of the processes and practices by which Boards engage in strategy is limited. In particular, very few empirical studies have penetrated the 'black box' of the Boardroom and examined the complex Board/Management interactions that amount to Boards 'doing' strategy. Here we address this gap, presenting an in-depth analysis of an unfolding process in which the Board and Management of a single organisation engaged in setting strategic direction over an 18-month period. We observed planning events, videorecorded Board meetings, analysed texts pertaining to the initiative, and spoke to key personnel. We adopt a 'strong' process approach which brings together strategy as process and as practice (SAPP). Our analysis is multi-modal: we track the iterative development of the strategy through documents/texts produced for Board meetings; and we adopt a sociomaterial approach in illuminating the entanglements of the human and nonhuman which constitute strategising. By considering events over a series of episodes, we have built a picture showing how micro-level practices in the Boardroom are layered incrementally in the emergence of strategy at organisational level. Relatedly, we show how these practices enable the Board to negotiate the tensions between control and service/collaboration. Hence the paper contributes to theory and knowledge around Board engagement in strategic activities.
\end{abstract}

Keywords Corporate governing · Interactive strategising · Procedural strategising · Sociomateriality $\cdot$ Video-based analysis

Cate Watson

cate.watson@stir.ac.uk

1 Faculty of Social Sciences, University of Stirling, Stirling FK4 9LA, UK 


\section{Introduction}

The function of Governing Boards has come under intense scrutiny in recent decades, following a number of high-profile corporate scandals which have uncovered negligence on the part of Boards in matters of strategy (Judge and Talaulicar 2017). This has led to the widespread introduction of Codes of Good Governance in both the for-profit and not-for-profit sectors. Such codes typically include an expectation that Governing Boards will be involved in shaping the organisation's strategic direction, and this extends beyond a monitoring function. The Financial Reporting Council (FRC 2018, p. 3; emphasis added), for example, states,

An effective Board defines the company's purpose and then sets a strategy to deliver it, underpinned by the values and behaviours that shape its culture and the way it conducts its business

Yet, knowledge of Board involvement in the development and realisation of strategy is limited (Bordean et al. 2011; Brauer and Schmidt 2008; Judge and Talaulicar 2017; Nadler 2004). A number of reasons have been advanced for this. First, little is known about how Boards do strategy (Hendry et al. 2010) and, indeed, there is lack of clear consensus about the role of Boards in relation to this (Hendry and Kiel 2004; Judge and Talaulicar 2017); second, scholars have cast doubt on the ability of theory, particularly agency theory, which has dominated much scholarship around the function of Boards, to adequately account for the complex and multidimensional involvement of the Board in matters of strategy (Brauer and Schmidt 2008; Cornforth 2004; Stiles 2001; Tricker 2005); third, little research has actually penetrated the 'black box' of the Boardroom to examine the processes and practices by which Boards engage in strategy, particularly in commercial organisations (Watson et al. 2020). This is compounded by a lack of clarity surrounding the term itself; 'strategy' embodies a number of normative assumptions which often go unchallenged, even in the academic literature (Townley 2014, p. 58).

While a focus on strategy in organisational studies has flourished in recent years with the growth of research that examines strategy as process (Burgelman et al.'s 2018; Pettigrew 2003; Sminia 2009; Whittington 2017) and as practice (see, for example, Chia and Mackay 2007; Jarzabkowski 2004; Jarzabkowski and Spee 2009; Whittington 1996, 2006), very little of this has informed research on Governing Boards. In particular, very few empirical studies have examined the complex Board/Management interactions that amount to 'doing' strategy, and hence how the 'micro' level of interaction and collaboration produces 'macrolevel' outcomes at organisational level and beyond (Kouamé and Langley 2018).

Strategy as process and as practice represent largely separate (and in some respects conflicting) research streams; the former from management research and the latter from sociology. Process and practice refer to different, though highly interdependent, phenomena, but they also encompass distinct forms of theorising (Kouamé and Langley 2018). Process implies temporality, the emergence of events over time, while practice is a way of doing things. In terms of research 
methodology, process research has tended to focus on developing process and variance models (explaining how outcomes develop over time; and predicting relationships between variables), whereas strategy as practice has drawn on the 'practice turn' in sociology (Whittington 2006). Practice theories assume 'that situated action and social structures are mutually constituted, that knowledge is embedded in practical activity and that human and nonhuman agency are inseparable' (Kouamé and Langley 2018, p. 562). Hence, the practice turn is located in sociomateriality, which sees the social, including language, embedded in the material (Orlikowski 2007).

While these two streams of research draw on different traditions, Burgelman et al. (2018) suggest a rapprochement is possible, founded on a 'strong process' approach which entails an 'ontological commitment' to the world as constantly becoming (Langley and Tsoukas 2017). This counters the tendency to privilege substance over process, disrupting the Newtonian view that processes are merely the forces that push substances around (Rescher 1996); rather, 'things', are sociomaterial enactments and hence 'materiality is seen as performance rather than as substance' (Dameron et al. 2015, p. S6). Burgelman et al. (2018) designate this 'combinatory' approach, which synthesises key themes from both research traditions, 'strategy as process and practice' (SAPP). SAPP views 'realised strategy' as an ongoing process punctuated by strategising episodes (Burgelman et al. 2018, p. 541).

SAPP emphasises the dynamic, complex and nascent qualities of strategy. A tension thus emerges between a strong process-oriented conceptualisation of strategy in SAPP and scholarly accounts of the role of the Board in strategic matters which tend to separate aspects of this. Thus, Brauer and Schmidt (2008) make a distinction between strategy formulation and strategy implementation; they argue that the former is 'widely understood' by scholars to mean a range of tasks, such as undertaking analyses of strengths/weaknesses, horizon scanning, development of strategic options, etc. In contrast, they suggest that strategy implementation is less clearly understood, though it falls within the control function of the Board in ensuring 'that the intended corporate strategy is in fact realized' (Brauer and Schmidt 2008, p. 651). Similarly, Judge and Talaulicar (2017) distinguish between the monitoring (or control) function of the Board in relation to strategic direction (either ex post monitoring or ex ante monitoring) and its service role (whether active decision-making or more indirect advice/counselling). This separation of Board strategic tasks becomes problematic, however, if a more fluid understanding of strategy as ongoing activity is adopted. Indeed, Leonardi (2015) talks of a 'blurry line' between strategy formulation and implementation. As a result of this, Hendry et al. (2010), drawing on the work of Jarzabkowski (2005), prefer to speak of procedural and interactive strategising. The former referring to the largely 'structural' features of formal Board meetings, 'the effect of which is to embed...strategy within the organisation's routine activites and hierarchy' (Hendry et al. 2010, p. 36); and the latter to actual involvement of the Board in the less formal spaces of 'away days' and strategic planning events, 'as a series of nested incidents, each of which has the potential to continuously construct and reconstruct shared meaning' (p. 37).

A research focus on forms of strategising rather than Board role potentially offers an approach more in sympathy with the theoretical orientation and methodological 
aims embodied in SAPP. However, this requires access to Boardrooms in order to study 'Boards in action' (Cadbury 2000). While a body of research is developing which is based on observation of Governing Boards, this still represents a very small proportion of the research carried out in this field (Watson et al. 2020). Of this, even less has employed video-based data collection. There is thus a pressing need to conduct empirical research inside Boardrooms in order to understand the complex processes and interactional dynamics that constitute Boards doing strategy. Here we address this gap, presenting an in-depth analysis of an unfolding process in which the Board and Management of a single organisation engaged in setting strategic direction over an 18-month period.

The case concerns a college of further education (FE) in Scotland. ${ }^{1}$ Colleges in Scotland are classified as public sector bodies with charitable status and though, strictly speaking, 'not-for-profit', exhibit many of the features of commercial organisations: colleges in Scotland raise income from commercial operations; they market services to clients in a highly competitive arena; they have the same range of commercial risks as other businesses; and, like for-profits today, they must attend to corporate social responsibility. Our findings are therefore of relevance to both the forprofit and not-for-profit sectors (Cornforth 2004; Farrell 2005). In other respects, of course, colleges differ from commercial companies, and in ways that arguably make their role more complex. They do not have shareholders, but they must work in partnership with schools, employers, and industry to meet the needs of the economy and the local communities they serve. They must also respond to a rapidly changing policy context, characterised by Norris and Adam (2017) as a state of 'political churn'; and, in Scotland, they are directly accountable to government through negotiated Outcome Agreements, ${ }^{2}$ which determine their level of government funding. Unusually, the college which is the focus of this study, Dundee \& Angus College (D\&A), has agreed to be named and has worked with us in co-producing this analysis.

Here, we investigate the practices emergent in the Board of Management meetings (BoMM) at D\&A as the material entanglements of the actants, human and nonhuman, which give rise to learning, understood as a "performative knowledge practice constituted and enacted by people and tools in complex sociomaterial collectives or assemblages' (Fenwick et al. 2012, p. 10); and we examine the evolution of strategy over time through a series of more or less bounded episodes, thereby adopting Burgelman et al.'s (2018) 'combinatory framework' for strategy as both process and practice. Thus, we agree with Langley et al. (2013, p. 5) that, 'how the past is drawn upon and made relevant to the present is not an atomistic or random exercise but crucially depends on the social practices in which actors are embedded'.

\footnotetext{
1 Although the term 'FE' is widely understood in the UK context as referring to post-compulsory education concerned with training and skills development, this term is disliked in Scotland since many FE colleges also deliver significant amounts of higher education, though mainly at subdegree level.

2 Scotland's colleges receive funding direct from the Scottish Government via the Scottish Funding Council (SFC). Outcome Agreements set out what colleges and universities plan to deliver in return for the funding they receive from the SFC. https://www.sfc.ac.uk/funding/outcome-agreements/outcomeagreements.aspx.
} 
The paper is structured as follows. First, we set out the case - the planning of a 5-year 'Future Strategy' for the College. As part of the study, we observed planning events, video-recorded Board meetings, analysed texts pertaining to the initiative, and spoke to key personnel. Our analysis is multi-modal: we track the iterative development of the strategy through documents/texts produced for Board meetings; and we adopt a sociomaterial approach in understanding how the human and nonhuman engage in the processes and practices that jointly constitute strategising. The paper thus contributes to theory and knowledge around the role of Boards in setting the strategic direction of organisations in two key areas. Specifically, we provide important insights into the processes and practices by which strategy is performatively enacted in the Boardroom, showing how the micro level of interaction produces the macro level of organisational strategy; and, relatedly, we show how these practices enable boards to negotiate the tensions between control and collaboration.

\section{The case: the emergence of strategy in the Board of Management meetings at Dundee \& Angus College}

The idea for a case study of D\&A emerged while we were undertaking a wider project on governing in colleges of further education in the UK. ${ }^{3}$ The aim of this research was to observe 'boards in action' (Cadbury 2000) in order to examine how the Governing Board contributes to achieving the strategic aims of colleges in meeting the needs of learners, employers and labour markets. We had negotiated video and/or audio access to Board meetings at these colleges for a year, along with observation of selected committee meetings and other events. Fortunately for us, we arrived at D\&A as they embarked on the process of setting a 5-year 'Future Strategy'. At the same time, we witnessed some interesting practices in Board meetings by means of which the Board was facilitated in becoming actively involved in strategising. Taken together, these suggested that a case study would provide valuable insights into the actions of the Board in doing strategy, which we here define as the processes and practices through which knowledge concerning the future direction of the organisation emerges.

While scholars of a more positivist bent may argue that case study lacks rigour and does not allow of generalisation, we counter that 'by studying the uniqueness of the particular, we come to understand the the universal' (Simons 1996). Crucial in generating theory from case study is differentiating the subject and object of the study:

The case that is the subject of the inquiry will be an instance of a class of phenomena that provides an analytical frame - an object - within which the study is conducted and which the case illuminates and explicates. (Thomas 2011, p. 23).

\footnotetext{
${ }^{3}$ Processes and practices of governing in colleges of further education in the UK'. https://fe-governing. stir.ac.uk/.
} 
In this case, the subject is D\&A, while the object to be explained is Boards' involvement in strategising. The case study explores these processes, and attendant practices, and thus enables connections to be made between the 'micro' level of the Board of Management meeting - the entangled interactions of human and nonhuman actants - and the 'macro' of strategy at organisational level.

D\&A was formed in 2013 by merger of two colleges, Dundee College and Angus College, and is one of the largest in Scotland. The Principal during the period of the study, Grant Ritchie, took up his appointment in 2015. The Chair of the Board, Angela McCusker, was appointed by the Scottish Government in 2014, as is required for all regional colleges in Scotland. At the time of the case study, the Board comprised around 17 members, including members of teaching and nonteaching staff, and the president and vice-president of the Students' Union. It should be noted that the Principal is also a member of the Board.

D\&A has crafted a narrative identity built around its 'improvement culture', epitomised in the implementation of its 2-year 'Good to Great' (G2G) strategy (2018-2020), which won the Campbell Christie Public Service Reform Award in 2018. The aim of G2G was to ensure that 'by 2020 Dundee and Angus College will be the outstanding model of how regional colleges in Scotland operate and how they impact on their local economy'. At the stage in which we started gathering data at D\&A in January 2019, they had just embarked on a process of developing a 5-year 'Future Strategy' that would eventually succeed G2G. It is not our purpose to evaluate either the strategy or its implementation. This case study concerns the emergence of strategy in Board of Management meetings (BoMMs), understood as the coming together of Senior Management and Board Members within the designated space, governed by the cultural norms of such events (for which the Inuit have the rather more succinct expression 'katimaniq').

D\&A holds four Board meetings a year, each lasting two hours. Papers for all meetings and events are packaged and circulated in pdf form in a timely manner, as is required by the Code of Good Governance for Scotland's Colleges (Good Governance Steering Group 2016).

\section{Time line of events}

The data on which we base this analysis comprise:

- Papers, documents and other artefacts produced for BoMMs and other strategic planning events;

- Videos of BoMMs;

- Fieldnotes of BoMMs and planning events;

- Interviews with members of Board and Management.

The key episodes are set out in Table 1 . We recognise that many activities which might broadly be conceived as strategising would have taken place 'off camera' - the

$\overline{4}$ https://scottishpublicserviceawards.holyrood.com/winners. 


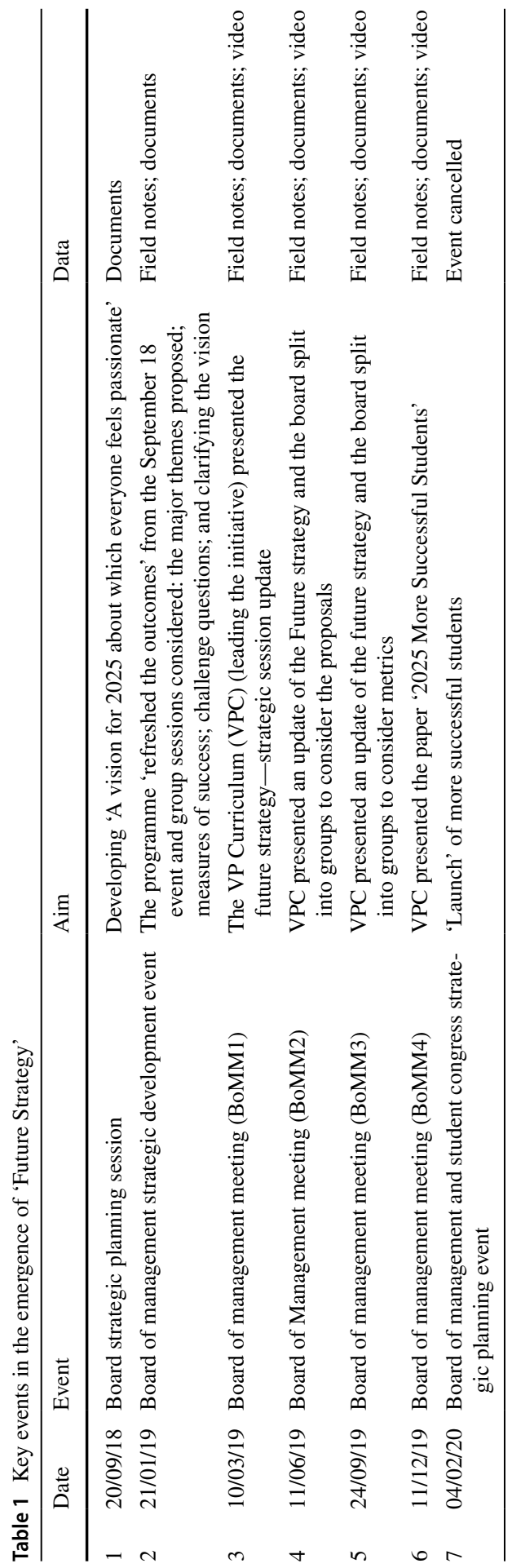


Chair told us, for example, that she had discussed 'Future Strategy' with the Principal prior to the initial, September 2018 event (Event 1):

'Yes, so I would start that process with the Principal, and give some thoughts of where I thought it might, they might want to think about going. And then they will, as an exec team, work on the strategy and then they will bring that back to me, and then back to the Board'.

However, our research concerned the entanglements of Board and Management in the formal spaces of the BoMM, and other related events. As Samra-Fredericks (2000, p. 251) notes, while much talk of relevance to Board decisions occurs outside the Boardroom 'in corridors, car parks, personal offices and the men's toilets', if it is significant it finds its way to the Boardroom since this is the space which legitimises Board actions.

\section{Data gathering}

Event 1 was not attended by us. All other events were observed and fieldnotes taken by the authors. Another Research Fellow, then on the team, observed the January 2019 planning event. Only Board meetings were videoed. The siting of video cameras and microphones is not a neutral act (Hindmarsh and Llewellyn 2018). In this case our options were limited-once a Board meeting had started it was not possible to alter the camera positions. Two cameras were positioned in such a way as to enable all participants to be seen, though this was not always possible. Choices thus surrounded ensuring the 'key' persons were in shot-usually this meant the Principal and the Chair, who often, though not invariably, sat next to each other. Similarly, the two external mics picked up all voices and problems arose if the meeting split into groups, as happened at D\&A. Thus, it was not possible to transcribe all the groups when the BoMM undertook groupwork, as occurred in BoMMs 2 and 3.

\section{Analysing video and text}

We present a multimodal analysis, examining the unfolding process through the various texts produced, and the interactions between Board Members and Senior Management in Board meetings and related events. In addition we shared the analysis with Senior Management and the Chair of the Board. As previously outlined, SAPP is located within process ontology (Rescher 1996). Commensurate with this, the analytical framework draws on sociomateriality. Thus we understand strategy as emerging in the entangled network of the human and nonhuman (documents and other technologies of meetings) from which learning emerges as a distributed phenomenon (Barad 2003). Crucially, sociomateriality views language as an embodied practice in which semiotic resources-gesture, eye contact, and emotion-all contribute as 'strategists weave visual narratives' (Gylfe et al. 2016). This is an aspect of strategising that is frequently overlooked by researchers, but as Dameron et al. (2015, emphasis added) point out, 'to programmatically ignore an audible or visible 
mode of behaviour in strategy work is to stunt our understanding of the phenomena that the strategy participants make available to each other'. Gaze and gesture are particularly important aspects of the embodied nature of language. Semiotic classification of gesture (Cassell and MacNeill 1991) generally recognises three main types: iconic (closely related to the semantic meaning of speech); metaphoric (corresponding to an abstract idea); and deictic (in some manner 'pointing'). Gaze too can be thought of as a form of deixis, and deictic words such as 'this' and 'that' can also function as 'verbal gestures' (Janney, 1999). Iconic and metaphoric gesture are integral to speech production, facilitating the organisation of thought, and may communicate (or at least be intended to communicate) meaning (Hostetter and Alibali 2008). Deictic gesture is complex and extends beyond merely indicating salience, rather it is a relational gesture that draws the other (human or nonhuman actant) in, implicating the other in the production of speech. In this way, through the three dimensional materiality of language, what Gylfe et al. (2016) refer to as "embodied cognition', strategy is woven.

We have adopted Burgelman et al.'s (2018) combinatory framework which integrates process and practice as the unfolding of 'realized strategy' in which are embedded episodes of 'deliberate' strategising. This has affinities with Kouamé and Langley's (2018, p. 577) 'hybrid strategy', which combines 'progression and instantiation', i.e., we provide a fine-grained analysis of the events over time, showing how activity produced Future Strategy during each event, and how it was then 'recontextualised and reshaped in the following period' (Kouamé and Langley 2018, p. 577). In order to do this we first undertook an analysis of documents produced for each event to highlight sequential changes and to reveal the emerging narrative threads. The development of strategy narratives, as carried by the documents, was then related to the video observations and the Board discussions in order to give insight into the enrolment of actants in this process. Video was analysed with the assistance of MultiUserTransana 3.32 ${ }^{\mathrm{TM}}$ software, which enables multiple transcripts to be developed in conjunction with the video (Woods and Dempster 2011). Transana supports transcription and navigation of video. Clips of analytically interesting parts of the meeting can be stored in 'collections' for in-depth analysis. Transana ${ }^{\mathrm{TM}}$ is capable of presenting split screens, but there is loss of quality and it cannot handle HD video. All videos were therefore converted to MP4 format. It was necessary to develop 'work-arounds' to ensure highest quality data were being used for analysis. This involved, for example, loading one camera angle to Transana and developing the transcript in conjunction with the second camera HD video viewed simultaneously, on the VLC media player.

Analysis of videos involved immersion in the data through repeated viewing and transcription of relevant episodes. (Transcription adopts a simplified form of Jeffersonian conventions, see Appendix 1). While this is one of the key affordances of video, we were aware that the very ability of video to allow repeated watchings may introduce uncertainties/ambiguities. ${ }^{5}$ Each viewing is itself an

\footnotetext{
5 Anecdotally, this phenomenon is reported by sport commentators in relation to the various video systems in place to adjudicate on decisions. Commentators sometimes report that what often appears on first viewing as clear cut becomes increasingly ambiguous with repeated viewings.
} 
unfolding process and repeated viewing may literally change what is 'seen'. Thus, our experience and interpretation of what we, as analysts, see is not only likely to be very different from our participants, it is also incapable of being fixed. The embodied materiality of language was particularly important in this and the role of gesture and the way documents/visuals were enrolled into the network by participants formed part of our analysis. We have provided a description of gestures rather than attempting to represent these graphically, which we feel is more helpful than providing still images.

We have very deliberately eschewed coding as a form of analysis, agreeing with St Pierre and Jackson (2014, p. 715) that coding 'has become a fetish, a superficial marker of a positivist scientism'. Rather, we have adopted a 'postqualitative approach' (the generic term given to qualitative approaches which reject coding) looking for the bit of data that 'glows' and 'seems to invoke something abstract or intangible that exceeds propositional meaning'(Maclure 2013, p. 661). Maclure elaborates: 'a fieldnote fragment or video image starts to glimmer, gathering our attention because it resists analysis, refuses to render up its meaning' (Maclure, 2013, p. 661). Undertaking this kind of analysis draws on an ethical rigour which demands a greater level of intimacy with both the data and the context for its production than is involved in coding. By this means we adopt an approach that is commensurate with 'strong' process research.

\subsection{Developing future strategy}

Here we give an account of the emergence of 'Future Strategy' in which we highlight significant strategy practices and follow three key narrative threads which emerged and became elaborated over time. These narrative threads concerned: the nature of the Board involvement in the process; the need to build on current strategic direction; and the importance of 'deeper engagement' with stakeholders.

\subsubsection{Event 1. Board strategic planning session}

The formal process of developing 'Future Strategy' began at the September 2018 planning event, attended by Board Members and Senior Management. The programme outlined the objectives and outcomes of the session which included three presentations setting out the political, economic, and social contexts, as well as the vision and aspirations of the College. Following these presentations, participants were divided into small groups to consider: 'Looking forward, how will the College look and feel like in 2025 through the eyes of (1) our students?; (2) our staff?; (3) our partners; and (4) our wider stakeholders?' Feedback was collated and presented in the document accompanying Event 2. 


\section{1/22 Vision:}

"To have deeper, more meaningful engagement with key partners and stakeholders in order to support the economic growth and social development of the Dundee \& Angus region by providing relevant, inspiring, innovative \& responsive courses and services in a way that is sustainable and efficient."

- Health \& wellbeing focused

- Fair \& equitable

- Trusted \& respected

- Employer of choice

- Personal development centred

- Leadership culture
- Responsive \& agile

- Building social equity

- Partner of choice

- Extending influence locally \& nationally

1: Deeper ingagement

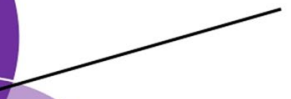

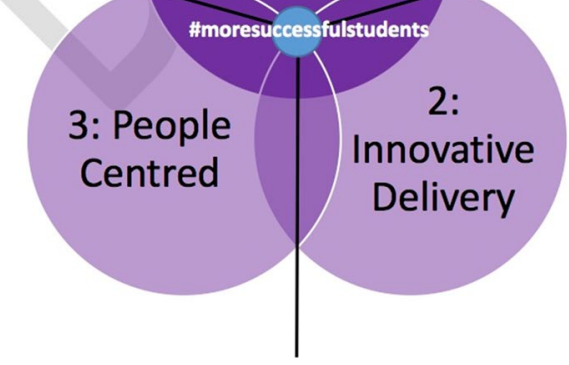

- Sector leading, modern courses \& services

- Inspirational

- Digital focused

- Data led decision making

- Modern \& flexible learning spaces

- Future focused

- Fully inclusive

Fig. 1 Future Strategy themes, first iteration

\subsubsection{Event 2. Board of Management strategic development event}

A second planning session followed in January 2019, the purpose and importance of which was emphasised in an email 'sent on behalf of' the Principal. In the email the Principal set out a key narrative thread for future strategic direction-that G2G 'has served us well ... but we now need to look ahead'; a second narrative thread concerned the role of the Board in 'strategy development', i.e., that this is a 'joint exercise' between Board and Senior Management. The Principal also introduced a 'core theme' of Future Strategy, namely 'Deeper Engagement'. (Spoiler alert: This became a highly contested area between Board and Management in what followed.)

This session aimed to 'refresh the outcomes' from the previous event and make links to 'a proposed framework to describe the strategic direction for the next 5 years'. Included in the Programme was a report on the initial groupwork planning session from Event 1, along with bullet-pointed feedback from the four groups. This was followed by a subheading: 'Overarching statement-Deeper Engagement', which set out a key part of the narrative: that $\mathrm{G} 2 \mathrm{G}$ was 'in many ways an internal exercise'. The new strategy 'will be characterised by looking outwards to partners and collaborators' (emphasis added). In addition, a Venn diagram was presented (Fig. 1). In the diagram Deeper Engagement appears as one of three overlapping 'themes' along with Innovative Delivery; and People Centred. These three themes 
meet in the middle, at a point labelled '\#moresuccessfulstudents'-a reference to a twitter handle used during the G2G strategy campaign, thereby creating a very material link to G2G.

In introducing the event, the Principal outlined its importance, rehearsing the narrative of D\&A's ascendency: 'only three or four colleges in Scotland have an improvement culture like Dundee \& Angus College', adding 'let's not lose that' before setting out the challenges facing the college and the need for collaboration in order to meet these challenges. He then handed over to VPC, who explained that these themes emerged from the group feedback from the September event, thereby reinforcing the narrative 'strategy is a joint exercise between the Board and the Senior Management'. The three themes were also linked to three 'strategic ambitions'.

Following this, participants were divided into groups to consider these themes. During this discussion, and the plenary which followed, criticism of each of the themes began to emerge from Board Members and a number of alternatives were suggested. Board Members also criticised the vision statement and suggested that the term 'strategic ambition' be replaced by 'pledge', as demonstrating greater intent. VPC asked for the notes from all the groups and undertook to work these up into a paper to be presented at the next BoMM.

\subsubsection{Event 3. Board of management meeting 1 (BoMM1)}

The documents supporting BoMM1 included collated feedback from Event 2 which refers to the criticism by Board Members of: the three core themes; the vision statement; and the term 'strategic ambitions'. This is a continuation of the narrative thread: 'strategy is a joint achievement of Board and Management'. The document also reiterated the necessity to build on G2G and introduced a new element in relation to this: the need for 'seamless transition'.

At BoMM1, VPC presented the Future Strategy paper to the whole Board, providing an account of the 'journey' so far and drawing out key narrative threads. Beginning with Event 1, VPC referred to the Scottish Government speaker and his 'massive emphasis on partnerships and collaboration', thereby locating Future Strategy in the external policy discourse. VPC also pointed to the need to ensure a seamless transition from $\mathrm{G} 2 \mathrm{G}$. He concluded by saying:

VPC: So really what you've seen in this Paper

is just the kind of story of how the strategy is evolving

and how how the kind of questions (.)

and your input's helping to kind of inform the next stages

[section of transcript not shown]

so (.) the Board ask tonight really is

you're happy so far with the story and the journey that has been proposed (.) if there's anything missing from what we said or any burning points um (.) and if you're happy for us to kind of move forward and produce um a revised stategy for the June meeting 
In analysing the data we were particularly interested in the use of indexicals, linguistic expressions with context dependent references, such as personal pronouns ('we', 'our', 'us', 'you'; emboldened in the excerpts presented). 'We' can be used in an inclusive and an exclusive way. In the excerpt above, VPC's use of 'we' refers to Senior Management. He distances himself from the Board by use of 'you'. As we show later, this is very different from what happens when the BoMM undertakes groupwork (BoMM2, BoMM3). The use of 'us' in the penultimate line is rather ambiguous, it could mean 'all of us' or 'the executive', but there is room for it to be interpreted differently by recipients. Indexicals thus construct spatiality, distance and closeness, in interactions between Board and Senior Management.

The paper was opened up to questions from the Board. Only one Board member asked a question and this concerned G2G rather than Future Strategy. This provided an opportunity for the Vice Principal (People and Performance) (VPP) to reinforce the need for seamless transition as a key narrative thread:

VPP: what we don't want is to get too (.)

'G2G's done now we're onto something else'

that would be really confusing for staff

and really difficult in terms of that transition

so we really need to look at-how are we all seamlessly moving from G2G into something else

Here, the use of 'we', certainly in the final instance, is inclusive. In the second line, VPP uses free indirect discourse (untagged movement between the minds of the narrator and character, in this case Senior Management or possibly the College) to dramatise the need for 'seamless transition'. This is the rhetoric of persuasion, enrolling the Board into the vision.

\subsubsection{Event 4. Board of management meeting 2 (BoMM2)}

'Future Strategy' appeared in the agenda and the minutes from BoMM1. The minute, as a summary of events carrying the narrative forward, noted that the Board's 'approval' was sought for the 'high level direction of travel'. The monitoring function suggested by 'approval' indicates a different role to 'jointly developing strategy', an ambiguity pointing up the complex relations between Board and Management.

The Future Strategy paper set out 'Progress to date' and summarised the comments from Event 2, noting the criticisms of themes/vision/ambitions made by Board Members, but also the comments made by the Board in relation to G2G's succession (i.e., the need for seamless transition), thereby securing legitimation from the Board for this. In this way, Future Strategy emerged as an aspect of the successful realisation of G2G. A revised graphic (see Fig. 2) replaced the Venn diagram: a layered circular diagram in D\&A corporate colours setting out the three themes, now renamed, following Board member input: Effective Partnerships, Future Focused, 


\section{Vision:}

"Working in partnership to change lives through learning and services."

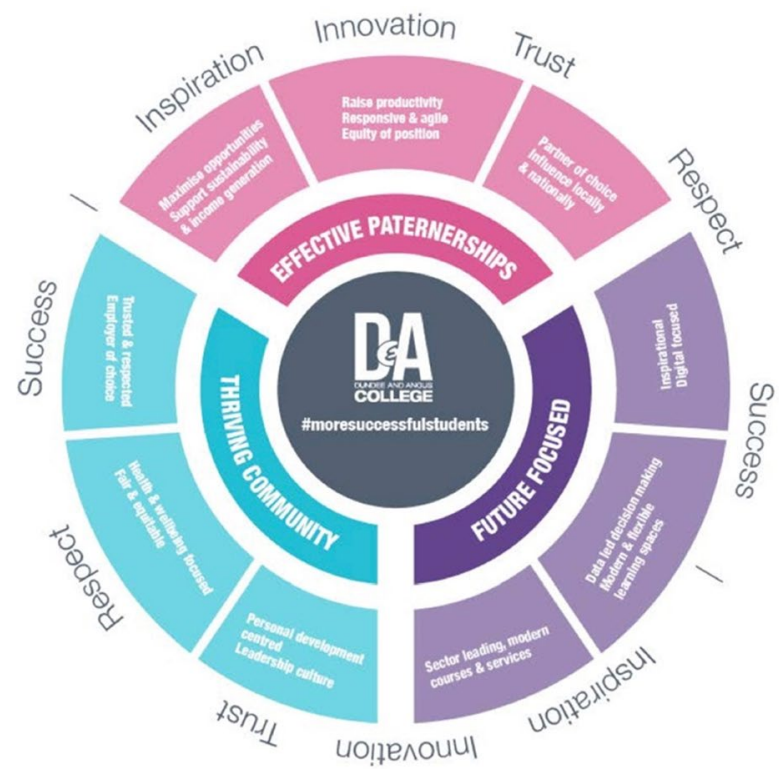

Fig. 2 Future Strategy themes, second iteration

and Thriving Community, along with their associated 'aims'. The D\&A values wrap around the diagram, and in the centre is '\#moresuccessfulstudents'.

Although 'Deeper Engagement' no longer featured as a core theme, it remained embedded in the Future Strategy paper as the 'focus' for strategy. The paper also quoted John Swinney, then Deputy First Minister of the SNP Scottish Government, who urged the need for 'deep collaboration', thereby firmly locating strategy in the macro level of policy discourse and adding authority to the continued focus on 'Deeper Engagement'.

At BoMM2, the discussion of the Future Strategy paper was immediately preceded by a report of the G2G project presented by the Principal, thereby creating a material and metaphoric enactment of the foundations of the new strategy going forward. At the end of the report the Chair pointed out some of the 'fantastic' achievements of G2G and explicitly linked this to Future Strategy and specifically the issue of transition adding:

Chair: I don't know if you guys have had any thoughts around how you might do that?

VPC: not to preempt the conversation but that whole (.) at the heart of what we said was the More Successful Students thing (.) $>$ and I think that has to stay at the heart of that $<$ and a lot of it actually is cos I think reported previously that a lot of (.) unintended consequences that have come out of the work that's been done that have come out of the work that's been done 
is the really strong partnership working that has been built

either externally or internally

and that to me is right bang at the heart of the next strategy

but people need to see [that link

Chair: [need to see that

VPC: they need to see that $\mathrm{G} 2 \mathrm{G}$ was the foundation

Chair: yeah

VPC's response is significant in that it was the first time More Successful Students was spoken in relation to Future Strategy. What was also notable was the emotional content of the utterance in which VPC enacted the narrative of seamless transition with its appeal to 'see that link' (in a way, urging his audience to feel the link), i.e., that 'strong partnership working', though not a planned aspect of G2G, became understood as the key factor behind its success. Throughout, this is accompanied by a range of gestures that enhance the meaning being communicated: hands gesturing outwardly and then inwardly to signify external/internal collaboration; a rolling gesture with both hands to underline 'the heart of the strategy' going forward; hands creating a 'platform' to convey that Future Strategy is emergent from the foundations of G2G. In this way gesture contributes significantly to the three-dimensionality of language and the emergence of strategy. VPC therefore skilfully aligns G2G and 'Deeper Engagement' and this is why 'Deeper Engagement' has to be the foundation of strategy going forward. This is emphasised through repetition, including that provided by the Chair. In this way, VPC's rhetoric seeks to 'move' the audience (Samra-Fredericks 2004) and this appeal is clearly directed at the Board as the 'people' and 'they' who need to understand this fundamental point.

Following this, the Chair divided the participants into three groups to address a number of questions in relation to Future Strategy: What do we agree with/not agree with?; Is there anything missing?; and, What changes do we want to see? The Principal prefaced groupwork with a few contextualising remarks, quoting the Deputy First Minister about the need for 'deep collaboration' adding,

Principal: the overarching idea I think about the deeper collaboration and partnership everybody gets ...

(Though, as it turned out, not everybody did get this.)

In this way, VPC, with his emotional appeal, and the Principal, in his more measured way, calling upon the authority of the Deputy First Minister, seek to persuade the Board of this crucial aspect of Future Strategy, enrolling others into the co-construction of strategy. The Future Strategy paper carries the narrative thread, but it is in the Board meeting that the narrative is very dramatically performed. 


\subsection{Groupwork}

The group which is the focus of the analysis presented here comprised the Chair, VPC, and three Board Members, BM1, BM2 and BM3.

In analysing groupwork we were concerned with the complex positioning of the speakers and the ways in which speakers enrolled the human/nonhuman actants into the narrative through gesture and language, particularly in the use of indexicals (personal pronouns) and demonstratives ('this', 'that'). The group had just started its deliberations when BM1 (who had not been present at earlier events) asked this question:

BM1: Who makes that up? [looking at 'Future Strategy' paper on his laptop] VPC: This was the Board

This was the exchange that triggered the idea for a case study; it is a piece of data that 'glows'. It neatly encapsulates the dilemma at the heart of strategy and the role of the Board. It calls up a feeling, a 'sense' that here we are dealing with complex, irresolvable, ambiguities around the interactions between Board and Management that constitute governing. '[T]his was the Board' provides the starting point for VPC's narrative. Through it, he weaves a complex plot of shifting identities, roles, and positions by which strategising is enacted.

In the exchange above the use of 'that' by BM1 positions himself as distanced from the process, while VPC's 'this' brings the Board inside. VPC accompanied this remark with a complex gesture, indicating with his left hand the Future Strategy paper, then, in a continuous rolling motion with both hands, index fingers pointing first towards himself, then the other members of the group, and back to himself again. There is thus, strictly speaking, a mismatch between word and gesture since the gesture, at the very least, implicates Senior Management in this process. Gesture-speech mismatches are a common phenomenon and there is some evidence that in such cases it is the gesture that is 'believed', or at least the words are 'filtered' through gesture to arrive at an interpretation (Janney 1999). The gesture underlines the ambiguity contained within the phrase 'this was the board'. VPC then uses BM1's question as an opportunity to give an account of the process so far, enabling a rehearsal of a key narrative, that of Board and Management 'working alongside' in the 'development of strategy'.

The use of 'we' is particularly striking in this account. 'We' is about signalling shifting identities, here indicating the complexity of interactions between Board and Management. Some research indicates that political speakers very consciously position themselves using these different referents through which they seek to manipulate, accomplish 'equivocation', or 'do' power (Inigo-Mora 2004; Moberg and Eriksson 2013). We do not mean to convey that VPC did this intentionally; nevertheless, it is clear that, in the use of indexicals and accompanying gestures, VPC sought to influence the discussion, enrolling others into his strategic vision, and implicating the Board in this process. The shifting uses of 'we' are evident in the transcript 
shown below, which is a continuous excerpt from the group discussion, but which for ease of reading we have divided into short sections.

VPC: $\quad$ so just to talk you through the process

[VPC returns to his seat and retrieves document related to Event 1]

Chair: the process so far

VPC: yeah (.) so far (.) we met we met in September

[shakes document]

and we had [name of Scottish Government speaker] in

[circles name on document with pen]

BM2: God was it September!

VPC: [looks at BM2] I know

Here the use of 'we' is inclusive, meaning Board and Management. BM2 positions herself as party to this process from the beginning (in contrast to BM1) through her interjection, and this is acknowledged idiomatically by VPC and through a look and smile, creating a complicity between them.

VPC: and we had [name of Scottish Government speaker] in who kind of talked about

what colleges need to be in the future

[continues pen circling action on the paper]

agile (.) collaborative (.) must be skills alignment.

[bringing hands together and apart]

and links with schools

[taps paper smartly with pen twice]

was the key things [name] kind of said

and from that we did a kind of (.)

[circling hands]

basically a brainstorming exercise

[holds both hands out with palms facing upwards]

and came up with the key themes which were 'deeper engagement' 'innovative delivery' and 'people centred'

[taps document each time as he says the key themes]

In the excerpt above the use of 'we' is again inclusive

so that was all worked up

[circles with right hand and then forms spherical shape with both hands]

and we came back in January with a more kind of worked up [.] version of that.

[points towards paper]

um and the Board had an opportunity at that point really to review that again

[looks at chair who is taking a drink and doesn't return look] 
Here, 'we' is arguably exclusive, referring to Management who had gone away and worked it up. The exclusive use of 'we' is confirmed in the next part of the utterance where 'the Board' is referred to and is hence distanced from Management.

in a lot of cases we didn't like the words 'deeper engagement' [BM2 nods several times] so there was (.) liked the overall three themes [gesture forming arch shape]

but that then evolved obviously into what you kind of see now

The use of indexicals here is curious and indicates some complex shifting in position. In the first line, 'we' is inclusive, but given that the words 'deeper engagement' had been brought to the BoMM in the Management's 'worked up' paper, this indicates a shift from a Management position to alignment with the Board (reinforced by BM2's nods). Distancing from his own role in the process, as member of the Senior Management team, seems to be indicated with the passive 'that then evolved' in the final line, but then separation between Board and Management is seen in the reference to 'you' (rather than 'we').

In developing his narrative, VPC used a number of gestures which enrolled other human and nonhuman actants. Thus, in the extracts above we see how gesture weaves documents into the narrative. In the first of these VPC shakes the paper, a deictic gesture lending considerable weight to his words through the authority of the printed document. In the first and second excerpts, the government speaker at the September planning event is brought into the narrative through the circling of his name on the document. In effect, this mobilises the external policy context (embodied by the speaker in his presentation) and hence lends further legitimacy to the developing strategy. This demonstrates the ways in which the 'macro' is enfolded into the 'micro' level of interaction. In the second excerpt, tapping the paper is a deictic gesture which performs the function of pointing. This goes beyond indicating 'salience' (as Roth and Bowen 2003, contend), rather it is a means of animating the document. The reciprocal enfolding of micro/macro indicates how each is constitutive of the other. In other places, gesture is metaphoric, matching words quite closely (the 'open' gesture of palms up which accompanies 'brainstorming' in the second extract; the arching shape in the fourth extract to indicate the 'overall three themes'). Gaze was also used to elicit support. Thus, VPC attempts to enrol the Chair to confirm the Board's involvement in the second extract which, however, fails as the Chair's attention was diverted. (Elsewhere, this tactic was successful and drew forth nods or 'yeah' from the person looked at or pointed to.) Through voice, gesture and animation of documents, VPC encapsulates the shifting identities and complex processes by and through which Board and Management are engaged in jointly producing strategy. This demonstrates the embodied nature of language and the complex three-dimensionality of interaction which constitutes strategising.

Throughout groupwork, the Chair and Board Members also used indexicals to indicate a range of positions, though this tended to be less marked than VPC. 'We' 
was most often used exclusively to mean the Board, but on other occasions, inclusive 'we' was used to refer to Board and Management, the College, or even more broadly the sense of the wider community as indicated below. This signalled the commitments and responsibilities of Board Members to the College and beyond.

BM2: you know (.) how do we help deliver a strategy? [The Board]

BM3: we're getting money er for to support some of that work as well because we have got such a various range of students. [The College]

BM1: but you're acknowledging the fact that you need to be equitable when you've got the demographics of the city that we've got. [External context]

Following this narrative account of the process so far, the discussion focused on the three questions, starting with: 'What do we agree with?'. In supporting this discussion, VPC referred to a previous Future Strategy paper to demonstrate how the comments made by the Board had been addressed by Management. This included the vision (sharpened up and now, by general agreement of the group, 'much snappier') and the change from 'ambition' to 'pledges':

VPC: ambitions became pledges

because ambitions sounds like

'oh well we would like [to do that'

BM2: (nods) [yeah - we will deliver

VPC: $\quad$ pledges are 'we will do this'

[pumps fist into palm of hand] .

Here, VPC uses free indirect speech to dramatise what was said at the Strategic Development Event (Event 2), which draws nods and agreement from BM2. Again, through the use of the indexical 'we', Board and Management are implicated in the strategy process. Following some further discussion the Chair sums up 'what we like' and in doing so enrols the graphic (Fig. 2) through deictic gesture:

Chair: so that's things that we like

we like the fact that it's a very clear purpose

we like the fact that there's three clear pledges

um I think (.) the visual

$>$ I mean not everybody likes that $<$

[gestures downwards with all fingers on both hands pointing at the graphic as if playing the piano]

but personally I like the visual image

[continues gesture while stirring hands over the image]

BM3: yeah

Chair: I think it makes it easy to understand and access $\uparrow$ 
VPC: I wanted also to be dead clear that the values need to surround all of this [VPC circles graphic on Chair's copy with pen, enacting 'surrounding']

Chair: yeah

VPC: dead important that we're wrapped around our values

[makes circular motion with both hands and then gestures as if weighing two objects]

Chair: yeah

VPC: because there is danger from staff

$>$ and I've heard it $<$

about initiative overload 'what does this mean for this that and the next'

but actually that is the $=$

[indicates towards diagram]

BM1: = that's your not for sale things though

VPC: yeah

needs to be [wrapped right around everything

BM1: [I like that I totally agree with you

BM2: that underpins everything

Chair: and I think the outside

[Chair circles diagram with pen]

but also that inside of it is [looks at VPC] about \#moresuccessfulstudents?

[Chair taps centre of diagram with pen]

VPC: that's the heart of it

$$
\text { [VPC taps Chair's copy of diagram smartly] }
$$

Chair: that's the wrap around [looks at BM2 and nods]

In analysing the use of PowerPoint in strategy meetings, Knight et al. (2018) suggest that such technologies give rise to strategic visibility which in turn prompts strategic resonance; the visual 'brokers thoughts, concepts and understandings that are difficult to describe in words alone' (Knight et al. 2018, p. 916). The graphic performs a similar function here, talking with the graphic enables the exchange and development of complex ideas as an integral aspect of 'strategising'. We see here, for example, how the action of the Chair in tapping the centre of the diagram is echoed in the VPC's comment, 'that's the heart of it'. While text is perceived linearly, an image is understood holistically, 'the perception of the whole is predicated on the basis of the relationship between the parts, rather than the identities of each component' (O'Halloran 2008, p. 448; original emphasis). This allows a spatial understanding of strategy to emerge: 'inside', 'at the heart', 'wrapped around'. In this case, the graphic was presented as hard copy, which arguably facilitates co-construction of meaning. Gesture animates the document in a way that would not be the same if the graphic was presented electronically. This highlights the affordances provided by particular technologies and hence how the nonhuman enters into strategy considered as assemblage. That the whole image takes precedence over the parts (Hostetter and Alibali 2008) was indicated by the fact that there was a typo in one of the three themes; 'effective paternships' [sic], that was not picked up until we pointed it out during the final BoMM we attended. 
The group continued to discuss the Future Strategy and especially what the Chair described as the 'step change' that the strategy would need to deliver. In defending his position, VPC argued that the step change would be provided by Deeper Engagement. This produced challenge from the Board Members:

\section{BM1: I just want to say (.)}

$>$ obviously you strike me as someone very intelligent $<$ very on the ball

but (.) y'know in 2025 is your statement going to be 'deeper engagement' y' know (.) ['Dundee \& Angus College we've got deeper engagement'

VPC: $\quad$ [yeah

BM1: I just dinna get it

not being critical

VPC: no (.) not at all

In this challenge BM1 creates a sharp distinction between Board and Management, both in use of 'your' in the fourth line and in free indirect speech which effectively dramatises how weak this will sound in five years' time.

Similar entanglements were evident in the other group we were able to transcribe. This group comprised a member of Senior Management and three members of the Board. This group focused on the three questions asked, applying these in turn to the three pledges. As they did this they referred extensively to the Future Strategy paper, pointing and using gesture. Use of 'we' shifted, with Board Members clearly identifying with the College, and the member of Senior Management shifting ambiguously between 'we' the management and 'we' Board/Management together. This group was much less clearly led by the member of Senior Management, though she acted as the scribe and in due course fed back to the whole meeting. The third group comprised the Principal, VPP and three Board Members. We could hear little of this, though we were able to observe their actions. The Principal stood, Future Strategy paper in hand, clearly orchestrating events. One Board Member pointed and gestured to the display on his laptop, while the others all referred to hard copy and gestured and made notes on their own and others' copies. Although we could not hear what was said, it was clear that the group was engaged animatedly in discussion.

Groupwork lasted for around $25 \mathrm{~min}$ and the Chair then recalled the groups who each presented feedback, which VPC said would inform the next iteration of the Future Strategy.

\subsubsection{Event 5. Board of management meeting 3 (BoMM3)}

At BoMM3, VPC presented a draft paper headed '2025 Strategic Purpose and Pledges' paper. This document was notable in formally naming the strategy More Successful Students. It was also notable in that 'Deeper Engagement' had disappeared altogether, remaining only vestigially as part of the Pledge, 'Effective partnerships': 'As a college we will establish and enhance deeper, more meaningful partnerships ...'. 
In presenting the paper to the whole Board, VPC again tended to use 'we' to refer to the executive or the College, and 'the Board' when referring to Board Members: 'The Board has been on a journey', 'we've had a number of update sessions and information sessions in which the Board has had the opportunity to input into'. This changed when he referred specifically to the groupwork sessions in which 'we' became more inclusive or in which some ambiguity was evident, and then shifted again in referring to the work of Senior Management in taking the strategy forward, and in particular in the naming of the strategy. Following the presentation, the Chair asked for questions/comments from the Board. There was one comment concerning clarification around the purpose of the strategy which was answered by the Principal. Here the Principal's use of 'we' in all cases referred to Senior Management. Thus, we might infer that the procedural practices of the formal BoMM supports separation of identities while groupwork has the potential to interrupt this, thereby facilitating interactive strategising.

Following the presentation the Chair split those present into three groups to consider the 'metrics', 'KPIs' (Key Performance Indicators), and 'milestones', to be incorporated into the final strategy document. Groupwork lasted for around 10 min and was followed by a 10 -min plenary. Due to the siting of the microphones it was not possible to clearly hear all three groups' deliberations in detail. We focus here on a group of six people comprising a member of Senior Management and five Board Members including two student Board Members (SBM1; SBM2). Here it was notable that the member of Senior Management did not seek to lead the group but provided information to Board Members on College matters: the metrics routinely collected (for example, around attainment and destination of students), and regulations concerning government funding which caps the numbers of full-time funded students. Notable, was the group's focus on the less easily measured metrics of achievement, in which again, the member of Senior Management was challenged by the Board. This was set in motion by a Board Member asking 'What does a 'more successful student' look like?' This prompted a discussion which enabled the group to performatively enact organisational values centring on meeting the needs of learners as well as performing the normative role of the Board in providing challenge, as the following extract shows:

SBM1: > personally coming from a student's point of view < I think the biggest thing to be a successful student [emphatic hand gesture indicating inverted commas round successful student]

is that getting involved (.)

is that putting on more for them to be involved in

for someone who maybe wouldn't speak to anyone (.) when they first come here

to then being running (.) being student ambassadors for clubs this year running a club y'know

that to me is hugely successful for a student like you [say 
[looks at BM3 who had previously spoken of valuing students'

BM3: achievements]

SBM1: it's not all about the grades it doesn't have to always be about the grades [open palm gesture looks at BM3]

are they just making those improvements

then the college can openly say (.) like 'we did that'

[nods several times looking round the group]

y'know that's that's huge in the successful students right there

VPP yeah

\section{[nods]}

I think the thing that we want

when we're looking at a strategy like this is a y'know

a relatively small number of metrics for each of the areas

because if you start having y'know

'here's a hundred and fifty different metrics'

[with right hand using all fingers prods the strategy document and then raises hand and brings it back down in a wavy motion onto document]

[as well then

BM3: [yeah yeah I

VPP some of the real big ticket things [that we want to

BM3:

[yeah I get that but this is a big ticket thing

you've put it in your vision 'changing li(huhhuh)ves' huh huh

so if it's in your vision that's a huge ticket event

so so I guess there is (.) I think you're right

[looks at SBM1]

what is the metric around that?

In this exchange, talk and gesture, including glances which enlisted support from others in the group, and hand movements weaving the authority of documents into the talk, were used to enable the group to perform different facets of strategising. SBM1 aligns herself with the student body, and in doing this enlists the support of others, particularly BM3, through nods and glances. VPP's response, however, does not orient to this but rather voices a pragmatic concern from the point of view of Senior Management, 'what we want', set against the wishes of the Board 'because if you start having', accompanied by a gesture which seems to perform, metaphorically, the likely outcome of too many KPIs. This draws forth challenge from BM3 (BM3's ambiguous laughter is particularly potent in this) manifested in the repetition of VPP's words and in the overtalking with neither willing to give way. What is clearly evident in this excerpt too, though, is the enactment of College values as putting the learner at the centre. This perhaps indicates a function of the Board that goes beyond instrumentality, concerning values and the construction of the organisation as the 'kind' it is. 


\subsubsection{Event 6. Board of management meeting 4 (BoMM4)}

The final BoMM was held in December 2019. Although the 2025 Strategy paper was included among the packaged papers, as always pre-circulated in pdf form, those present at the meeting were also provided with a hard copy of the document. The 8-page document, headed '2025 Strategy-More Successful Students, BOARD OF MANAGEMENT, Wednesday 11 December 2019', was produced in full colour with photographs and coloured graphics, and printed on very high quality, stiff, paper. The diagram (Fig. 3) was slightly altered, with the D\&A values now in the centre and the Key aims removed and placed underneath in bulleted form with accompanying icon. The pledges are now numbered, Effective Paternships [sic] (1), Future Focused (2), and Thriving Community (3). That the document had been produced for the Board, rather than for wider dissemination, was indicated by the final page which set out next steps and the Board 'ask' at this meeting: to approve the 'strategy, vision and pledges' and agree that the metrics provided 'represent the aspirations of the Board of Management'. The high production values of the hard copy perhaps signalled 'closure' in a way that the electronic pdf (which all Board Members received) did not. At the meeting the Chair asked VPC to go through the pledges and the accompanying metrics. The Principal and VPP also provided further detail to answer questions put by the Board which focused on the metrics. The Chair formally put the 'asks' to the Board and silence and a few nods was taken as affirmative.

\subsubsection{Event 7. Board of management and student congress strategic planning event}

The planned launch of More Successful Students in February 2020, at a joint event of the Board and the Students' Union, was cancelled due to unforeseen circumstances.

\section{Discussion: strategy as process and practice}

Here we draw together the findings from the case study and consider how these might further thinking around board engagement in strategising. Specifically, we make connections between two key questions concerning governing: (1) How do boards negotiate control/collaboration?; and (2) How does the micro level of interaction produce the macro level of organisation?

\subsection{Strategy as process}

Process concerns temporality, the unfolding of events over time. Kaplan and Orlikowski (2013, p. 965) speak of the 'temporal work' undertaken by strategisers in interpreting past, present and future to 'construct a strategic account that enables concrete strategic choice and action'. This was very evident in the case study presented here in relation to the origins of More Successful Students in G2G. SAPP recognises the recursive nature of strategising as 'realized strategies of the past feed 
into the strategising episodes in the present' (Burgelman et al. 2018, p. 541), but it was evident too in the way the past was narratively rewritten in order to make it relevant to the future, with More Successful Students constructed by VPC as emerging from the 'unintended outcome' of G2G.

Temporality is experienced differently by Board and management. The work of the Board is inevitably episodic. While Senior Management may be immersed in strategy and operational matters on a daily basis, for Board Members this is patently not the case. The narrative of Future Strategy has to be carried through the process and reiterated, rehearsed and re-enacted in each step. It largely falls to the documents produced for the Board (minutes, agendas, Future Strategy papers) to carry the threads. Thus the Future Strategy paper produced for each BoMM carried increasing authority and textual agency (Cooren 2004) with each iteration, but it also represented a site of contest in the Boardroom as strategy narratives were performatively enacted by Senior Management and Board Members.

As indicated previously, three key narrative threads were set in motion by the Senior Management at the start of the process and required intense narrative work for their sustenance. The first concerned the process itself, i.e., that strategy development is a joint exercise undertaken by Senior Management and the Board working alongside. This narrative was rehearsed explicitly by Senior Management throughout the process and enacted through the practices entered into at each BoMM.

From the outset, Management was keen to stress that setting strategic direction was a joint endeavour undertaken by the Board and Senior Management. At the end of the 18-month process it is interesting to reflect on this and to examine the extent to which the Board did genuinely 'work alongside' Senior Management in, as Management put it, 'developing strategy'. Clearly, Senior Management took the lead in setting out the foundations of Future Strategy. By emphasising the need to build on the success of G2G, and ensuring a seamless transition, Senior Management laid out the direction of travel. This steer was largely accepted by the Board and to this extent the narrative of 'joint development' of strategy could be questioned. However, it should be remembered that Management was itself responding to a very strong steer from government. The external policy context, represented by and embodied in, the person of the Scottish Government speaker at Event 1, was brought sharply into focus as a strategic driver. The etymological origin of governance is 'steering at a distance' (Kickert 1991), this was illustrated here showing how the macro-level of policy is interpolated into strategy at the level of the organisation.

Clearly, the Board was engaged at all stages of the process, from the initial event in September 2018 to the launch of 'More successful students' in 2020, and exerted considerable influence. This was particularly evident in the naming of themes, the development of 'strategic pledges', and the clarification of 'vision'. It was evident too in the challenge presented to 'Deeper Engagement'. However, throughout the process there were a number of different expectations of the Board. At times the Board did work alongside Management on developing Future Strategy, but on other occasions the Board 'ask' was to 'provide advice' and to 'give approval' for decisions. Thus, curiously, the Board was asked to advise on and approve what it had ostensibly jointly produced alongside Management. The blurring of roles introduces an element of ambiguity into practices of governing which challenges dominant 
theories, particularly Agency theory. However, it was evident that these different enactments of governing tended to take place in different spaces created within the Boardroom - 'working alongside' taking place within the intimate spaces of group work and 'giving approval' in the larger context of the Boardroom. This indicates the ways in which the practices of the governing body can be drawn on in negotiating the tension between control and collaboration/service (Judge and Talaulicar 2017), discussed further below.

The second and third narratives concerned Future strategy: the mythical origins of 'More successful students' in G2G and the need for a seamless transition between them; and 'Deeper Engagement' as the overarching focus for Future Strategy. While the Board largely accepted the second narrative, they resisted the third. From the start, the need to 'build on the success of G2G' was emphasised. Through the repetition of the achievements of $\mathrm{G} 2 \mathrm{G}$, in which 'More successful students' was securely located, D\&A's 'improvement culture' was rehearsed. Indeed, G2G pervaded the emergence of 'More successful students', from adopting a twitter handle from the G2G campaign as the naming of the strategy, to the way in which G2G almost invariably immediately preceded Future Strategy as an agenda item. The line between implementation and formulation of strategy thus becomes very 'blurry' (Leonardi 2015 ) in the intermingling of G2G and the emergence of 'More successful students'. A central part of the narrative of the origins of 'More successful students' concerned what VPC referred to as the 'unintended consequence' of G2G, which held that a crucial element of its success was the collaboration with stakeholders that had been engendered. While G2G had been 'internally focused', 'More successful students' would, VPC said, build on this, looking outward and fostering 'Deeper Engagement' with partners. It was this aspect that created the greatest resistance from the Board. Despite the Principal's claim that 'everybody gets' the idea of 'deeper collaboration' it seems that this was the aspect of 'More successful students' that not everyone did get. As a result, Deeper Engagement was successively downplayed in each iteration of the Future Strategy document until it was all but effaced, the term 'deeper' remaining only as a step in the theme 'Effective Partnerships'. While this potentially threatened the narrative of seamless transition assiduously constructed by Senior Management, i.e. that 'More successful students' emerged through the implementation of G2G which had shown the importance of collaboration, it resulted in the clarification of the strategy as centred on the learner, rather than on partnership, and this was, arguably, not an insignificant change demanded by the Board.

\subsection{Strategy as practice}

The analysis draws out the entanglements and complexities of the emergence of Future Strategy. The findings offer support for Hendry et al.'s (2010) distinction between procedural and interactive strategising. Procedural strategising 'relies on formal administrative activities' in which Boards 'review, approve and monitor strategy' (Hendry et al. 2010, p. 38). Interactive strategising, conversely, involves 'faceto-face' interaction and negotiation between Senior Management and the Board which requires 'open communication'. Whereas procedural strategising is the norm 


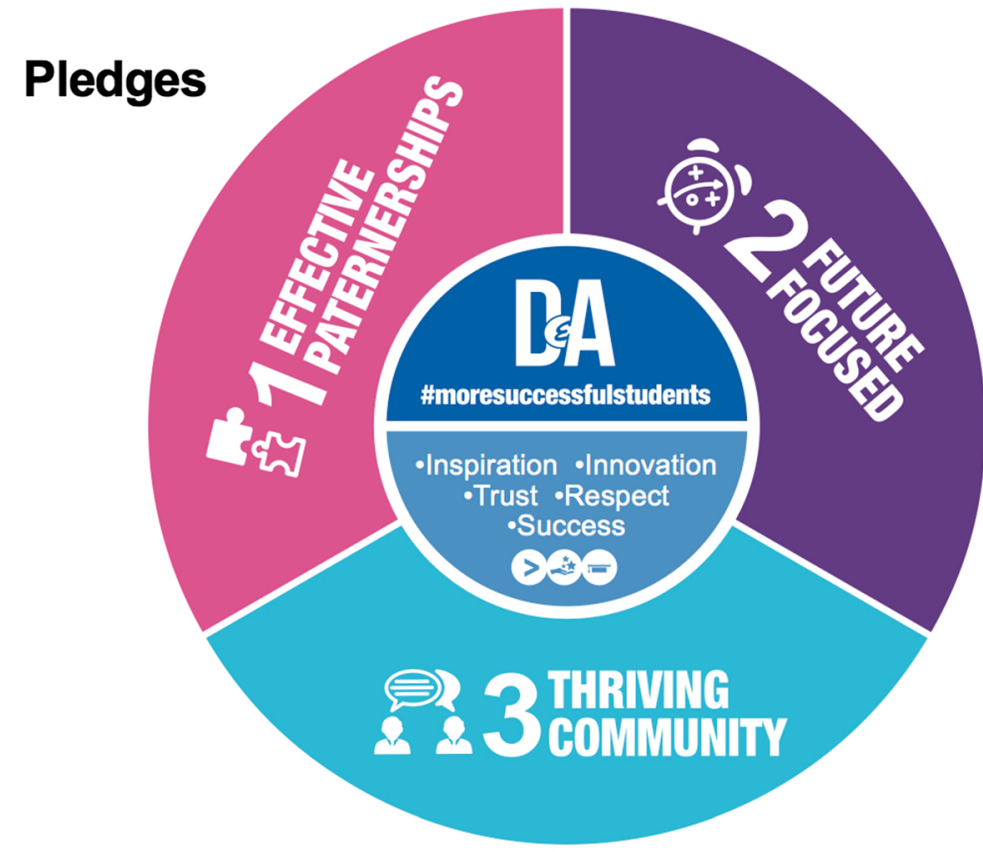

1. How will we deliver on our Effective Partnerships Pledge?

- By maximising opportunities for our learners and clients

- By prioritising sustainability \& income generation

- By playing our part in raising the productivity of the region

- By being responsive \& agile

- By raising the profile of Further Education both locally \& nationally

- By being a partner of choice

- By influencing key stakeholders partners both locally \& nationally

\section{How will we deliver on our Future Focused Pledge?}

- By co-designing sector leading, modern courses \& services

- By being inspirational \& inclusive

- By ensuring we are digitally enabled $\&$ developed

- By using data to better inform our decision making

- By providing modern \& flexible learning spaces

\section{How will we deliver on our Thriving Communities Pledge?}

- By being health $\&$ wellbeing focused

- By responding to the Global Climate Emergency

- By ensuring we are trusted \& respected

- By being an employer of choice

- By being self-reflective \& personal development centred

- By fostering a leadership Culture

Fig. 3 Future Strategy themes, final version 
for Board meetings, interactive strategising is more likely to occur in less formal contexts such as away days and 'strategy workshops'. In this case study, the practices associated with the formal Board meetings can be characterised as 'procedural'presentation of a paper by Senior Management followed by the Chair inviting comments or questions. On such occasions the Board 'ask' was to 'provide advice' and 'approval' for decisions. These exchanges were characterised by a clear separation of the identities of Board and Management. Groupwork, by contrast, encouraged 'open communication'. Groupwork interrupted the formal aspects of Board meetings ensuring that interactivity was maintained throughout the cycle of Board meetings, and was not just evident during strategic planning sessions.

Groupwork, as a practice of strategising, was designed by the Chair to encourage, as she put it, 'diversity of thought' and ensure that the voices of all Board Members could be heard. The Chair also used groupwork to secure 'buy-in and commitment to' the strategy. While these were the espoused purposes of groupwork, our video analysis revealed a number of functions performed by groupwork in BoMM2 and BoMM3. In BoMM2, VPC engaged in intense narrative work around the developing strategy in the face of what he later (maybe only half jokingly) described as a 'tough crowd'. In BoMM3, groupwork enabled Board and Management to performatively enact college values constructiong the learner as a matter of concern. What was particularly evident in groupwork was a blurring of identities evidenced through the shifting use of indexicals (Bucholtz and Hall 2008). When addressing the BoMM, Senior Management tended to use 'we' to refer to Management and 'you' when referring to the Board. In groupwork this changed. The sociomaterial performance of identities, enacted through the use of indexicals, gesture, and the enrolment of human and nonhuman actants, in which documents and visuals played a key role in organising strategy talk, produced a blurring of the boundary between Board and Management. Thus, we might infer that the practices of the formal BoMM, presentation of papers followed by questions from the Board, are predicated upon a distinct separation of identities of Board and Management and it is this that is interrupted through groupwork. This does not mean that other practices of the Board which depend on distance for their enactment, such as scrutiny, did not occur in the group context; or conversely, that interactivity was never achieved in the formal elements of the Board meeting. Rather, as practice, groupwork tended to promote interactive strategising, while the formal Board meeting supported the practices associated with procedural strategising. Like Hendry et al (2010) we do not claim that one is 'better' than the other, each has its place: Boards must work alongside management and they must stand apart. This is the ambiguity that everywhere inhabits governing.

\subsection{Strategy: the role of the board}

In an exhaustive review of board involvement in strategy, Judge and Talaulicar (2017, p. 54) refer to the tension between the control and service/collaboration roles as 'a delicate balance with which every board must wrestle'. This was evident in findings presented here, and the three key narrative threads identified all concern 
this challenge. Control and service clearly relate to the dominant theories of governing: agency/management hegemony and stewardship respectively, which are largely viewed as incommensurable and antagonistic. As Cornforth (2004), and others, have indictated these theories provide very blunt instruments for theorising the complexities and ambiguities of governing, 'only illuminating a particular aspect of the board's work' (Cornforth 2004, p. 19). Instead, Cornforth (2004) draws on the 'paradox turn' in organisation studies (Smith and Lewis 2011; Sundaramurthy and Lewis 2003) in understanding the complexities of board role. But, if dominant theories 'partially illuminate' they also necessarily obscure. More than this, they may actively obfuscate, influencing constructions of the role of the board. To some extent, it may be that boards experience the 'pressures to both control and partner senior management' (Cornforth 2004, p. 21) as a result of the normative expectations placed upon them by codes of 'good governance'. These normative expectations create ritual enactments in the boardroom (Hendry and Seidl 2003, p. 192),

communicating to the organisation and its stakeholders that all is well and under control, and for this purpose the separation of structures and routines marks out the meetings as 'sacred' territory within which ritual observance, not critical reflection, is required.

This suggests that the 'paradox' (or ambiguity) may lie between 'ritual observance' and 'critical reflection' rather than control and service per se. Paradoxes hold a special fascination for academics, but as Demb and Neubauer (1992) say, 'Paradoxes abound in business. Once sensitized, we realize that managers deal with them every day' Smith and Lewis (2011). propose that separating the poles of the paradox, creating spatial/temporal distance between them, is one way in which these tensions may be 'lived with'. Groupwork thus constitutes a different space for strategy work in which the 'ritual engagements', are suspended and 'critical reflection' may occur. In this way, spatial/temporal distance is modulated through a series of 'instantiations' (Kouamé and Langley 2018) in which sociomaterial enactments are central.

\section{Conclusions}

In conducting this research we have focused on the ephemeral and overlooked, showing how the minutiae of interaction are critical to the development of strategy at organisational level. Examining gesture and nods, and noticing the apparently inconsequential, is central to understanding how the micro and macro are entangled and unfolding in the performance of strategising. Crucially, our research helps to illuminate 'a blind spot... around how bodily and material resources are employed... to accomplish strategic work' (Jarzabkowski et al. 2015, p. S28). However, as process researchers, whose preference is to take a 'deep dive' into the episodes that provide our data, we are aware of the need to make wider claims (Abdallah et al. 2019). A major challenge for SAPP research is to produce analyses which show how interactions in the Boardroom give rise to macro-level outcomes (at the organisational level and beyond). Here, we have adopted an approach based on 'progression and instantiation' which considers 'different practices over successive periods and 
analyses how they instantiate emerging outcomes over time' (Kouamé and Langley 2018, p. 576). By considering events over a series of episodes, we have built a picture showing how micro-level practices in the Boardroom are layered incrementally in the emergence of strategy at organisational level. Key to this is the production of texts and their enactment in the Boardroom, hence the importance of recognising the embodied nature of language and the significant role of gesture as a means to animate texts. Thus, we see recursively how texts acquire authority and demonstrate agency, but this depends on their ongoing enactment in the Boardroom. But we see, too, from the other direction, how the macro level of policy is inserted at the micro level of the Boardroom. For example, here we have shown how policy, at the outset embedded and embodied in the person of the Scottish Government representative at Event 1, became interpolated into Future Strategy. In this way, the 'macro' of national policy is enacted through the 'micro' of Board interaction. Indeed, it may be an unhelpful essentialism to think in terms of micro and macro. In effect, both are mutually implicated in the constitution of organisation (Cooren, 2004).

Throughout this research we have been privileged to observe at first hand the processes and practices through which strategy is enacted in the Boardroom. Our work challenges dominant theories. In 2005, Tricker (2005, p. 16) argued that 'corporate governance, as yet, does not have an accepted theoretical base or commonly accepted paradigm'. This is probably still true today. The idea of an overarching, one-size-fits all, 'theory' of corporate governing was always an illusion. Instead of imposing rigid models we should instead acknowledge the complexity of board practices, embracing a radical undecideability: 'both/and' rather than 'either/or'.

Of course, the idea that there is no one-size-fits all explanation which says what governing 'is' may not be a particularly novel conclusion. Certainly, this has been a recurrent theme since the introduction of contingency theory in the 1960s, but here we have gone beyond this in promoting ambiguity as a legitimate framing of board action: boards do, indeed perform contradictory roles simultaneously. Here we have revealed how this is achieved as an accomplishment of Board and Management in collaboration. In particular, our work has shown how processes and practices modulate distance between Board/Management in negotiating the contradictions and tensions in board roles, and we have brought attention to bear on the sociomaterial enactments through which boards do this.

The challenge for boards, and particularly Chairs, lies in determining how ambiguities can be channelled and managed towards effective outcomes. Here we have shown how the practices of the governing body can contribute to this. Hence, the case study has implications for practice. Most notably, the way in which the Chair orchestrates the Board Meeting is crucial. Codes of 'Good Governance' stress the key role of the Chair. Relatively few studies have drawn on observational methods, as opposed to gathering retrospective accounts from actants, to elucidate why this is so and how the role is enacted. (This is too large a subject to go into here, see Watson et al. 2020 for a review). Here we have seen that forms of strategising, and the practices which support these, contribute in different ways to the emergence of strategy over time. This requires a sophisticated understanding of the multiple contexts in which strategy happens and the ways in which these may be drawn on. It also 
requires an appreciation of complex interactions of participants and the affordances of the various technologies, such as the use of groupwork, that constitute practice. This is a nuanced task which requires both an appreciation of the ebb and flow of events, and an understanding of the ambiguous nature of the Board 'ask'. We suggest that in the case study here these were clearly evidenced, contributing towards an understanding of how boards 'add value' to the organisation.

Acknowledgements We would like to express our very sincere gratitude to the Board and Senior Management of Dundee \& Angus College for privileged access to the Boardroom and for their help and cooperation in preparing this paper. We would also like to thank two anonymous reviewers for their comments on an earlier draft. Peer review is an act of astonishing generosity in academia and we are grateful for it.

Funding This research was funded by the Economic and Social Research Council. ES/R00322X/1.

Availability of data and materials Not applicable.

Code availability Not applicable.

\section{Compliance with ethical standards}

Conflicts of interest The authors declare that they have no conflict of interest.

Open Access This article is licensed under a Creative Commons Attribution 4.0 International License, which permits use, sharing, adaptation, distribution and reproduction in any medium or format, as long as you give appropriate credit to the original author(s) and the source, provide a link to the Creative Commons licence, and indicate if changes were made. The images or other third party material in this article are included in the article's Creative Commons licence, unless indicated otherwise in a credit line to the material. If material is not included in the article's Creative Commons licence and your intended use is not permitted by statutory regulation or exceeds the permitted use, you will need to obtain permission directly from the copyright holder. To view a copy of this licence, visit http://creativecommons.org/licen ses/by/4.0/.

\section{Appendix 1. Transcription conventions.}

(.) micro pause, less than $0.2 \mathrm{~s}$.

[] overlapping speech.

$><$ words spoken faster than surrounding talk.

$=$ latching i.e. talk continuous from one speaker to the next.

$\uparrow$ marked upward intonation.

Huh-laughter.

\section{References}

Abdallah, C., Lusiani, M., \& Langley, A. (2019). Performing process research, standing on the shoulders of giants research methodology in strategy and management (pp. 91-113). Emerald Publishing Limited: Bingley.

Barad, K. (2003). Posthumanist performativity: Toward an understanding of how matter comes to matter. Signs Journal of Women in Culture and Society, 28(3), 801-831. 
Bordean, O., Borza, A., \& Maier, V. (2011). The involvement of boards in strategy implementation. Review of International Comparative Management, 12(5), 986-992.

Brauer, M., \& Schmidt, S. L. (2008). Defining the strategic role of boards and measuring boards' effectiveness in strategy implementation. Corporate Governance: The International Journal of Business in Society, 8(5), 649-660.

Bucholtz, M., \& Hall, K. (2008). Finding identity: Theory and data. Multilingua, 27(1-2), 151-163.

Burgelman, R. A., Floyd, S. W., Laamanen, T., Mantere, S., Vaara, E., \& Whittington, R. (2018). Strategy processes and practices: Dialogues and intersections. Strategic Management Journal, 39(3), 531-558.

Cadbury, S. A. (2000). The corporate governance agenda. Corporate Governance: An International Review, 8(1), 7-15.

Cassell, J., \& McNeill, D. (1991). Gesture and the poetics of prose. Poetics Today, 12(3), 375-404.

Chia, R., \& MacKay, B. (2007). Post-processual challenges for the emerging strategy-as-practice perspective: Discovering strategy in the logic of practice. Human Relations, 60(1), 217-242.

Cooren, F. (2004). Textual agency: How texts do things in organizational settings. Organization, 11(3), 373-393.

Cornforth, C. (2004). The governance of cooperatives and mutual associations: A paradox perspective. Annals of Public and Cooperative Economics, 75(1), 11-32.

Dameron, S., Lê, J. K., \& LeBaron, C. (2015). Materializing strategy and strategising materials: Why matter matters. British Journal of Management, 26(Suppl 1), S1-S12.

Demb, A., \& Neubauer, F. F. (1992). The corporate board: Confronting the paradoxes. Long Range Planning, 25(3), 9-20.

Farrell, C. M. (2005). Governance in the UK public sector: The involvement of the governing board. Public Administration, 83(1), 89-110.

Fenwick, T., Nerland, M., \& Jensen, K. (2012). Sociomaterial approaches to conceptualising professional learning and practice. Journal of Education and Work, 25(1), 1-13.

Financial Reporting Council. (2018). Guidance on board effectiveness. London: FRC.

Gylfe, P., Franck, H., Lebaron, C., \& Mantere, S. (2016). Video methods in strategy research: Focusing on embodied cognition. Strategic Management Journal, 37(1), 133-148.

Good Governance Steering Group. (2016). Code of good governance for Scotland's colleges. Retrieved from: https://www.cdn.ac.uk/projects/governance-leadership-and-management/gover nance/

Hendry, K., \& Kiel, G. C. (2004). The role of the board in firm strategy: Integrating agency and organisational control perspectives. Corporate Governance: An International Review, 12(4), 500-520.

Hendry, K. P., Kiel, G. C., \& Nicholson, G. (2010). How boards strategise: A strategy as practice view. Long Range Planning, 43(1), 33-56.

Hendry, J., \& Seidl, D. (2003). The structure and significance of strategic episodes: Social systems theory and the routine practices of strategic change. Journal of management Studies, 40, 175-196.

Hindmarsh, J., \& Llewellyn, N. (2018). Video in sociomaterial investigations: A solution to the problem of relevance for organizational research. Organizational Research Methods, 21(2), 412-437.

Hostetter, A. B., \& Alibali, M. W. (2008). Visible embodiment: Gestures as simulated action. Psychonomic bulletin \& review, 15(3), 495-514.

Íñigo-Mora, I. (2004). On the use of the personal pronoun we in communities. Journal of Language and Politics, 3(1), 27-52.

Janney, R. W. (1999). Words as gestures. Journal of Pragmatics, 31(7), 953-972.

Jarzabkowski, P. (2004). Strategy as practice: Recursiveness, adaptation, and practices-in-use. Organization Studies, 25(4), 529-560.

Jarzabkowski, P. (2005). Strategy as practice: An activity-based view. London: Sage.

Jarzabkowski, P., Burke, G., \& Spee, P. (2015). Constructing spaces for strategic work: A multimodal perspective. British Journal of Management, 26, S26-S47.

Jarzabkowski, P., \& Spee, P. A. (2009). Strategy-as-practice: A review and future directions for the field. International Journal of Management Reviews, 11(1), 69-95.

Judge, W. Q., \& Talaulicar, T. (2017). Board involvement in the strategic decision making process: A comprehensive review. Annals of Corporate Governance, 2(2), 51-169.

Kaplan, S., \& Orlikowski, W. J. (2013). Temporal work in strategy making. Organization Science, 24(4), 965-995. 
Kickert, W. J. M. (1991). Applicability of autopoiesis to administration science. In R. J. Veld, C. J. A. M. Termeer, L. Schapp, \& M. J. W. Van Twist (Eds.), Autopoiesis and configuration theory: New approaches to societal steering (pp. 193-205). Dordrecht: Springer.

Knight, E., Paroutis, S., \& Heracleous, L. (2018). The power of PowerPoint: A visual perspective on meaning making in strategy. Strategic Management Journal, 39(3), 894-921.

Kouamé, S., \& Langley, A. (2018). Relating microprocesses to macro-outcomes in qualitative strategy process and practice research. Strategic Management Journal, 39(3), 559-581.

Langley, A., \& Tsoukas, H. (2017). Introduction. In A. Langley \& H. Tsoukas (Eds.), The SAGE handbook of process organization studies (pp. 1-26). London: Sage.

Langley, A. N. N., Smallman, C., Tsoukas, H., \& Van de Ven, A. H. (2013). Process studies of change in organization and management: Unveiling temporality, activity, and flow. Academy of Management Journal, 56(1), 1-13.

Leonardi, P. M. (2015). Materializing strategy: The blurry line between strategy formulation and strategy implementation. British Journal of Management, 26(S1), S17-S21.

MacLure, M. (2013). Researching without representation? Language and materiality in post-qualitative methodology. International Journal of Qualitative Studies in Education, 26(6), 658-667.

Moberg, U., \& Eriksson, G. (2013). Managing ideological differences in joint political press conferences: A study of the strategic use of the personal pronoun 'we.' Journal of Language and Politics, 12(3), 315-334.

Nadler, D. A. (2004). What's the board's role in strategy development?: Engaging the board in corporate strategy. Strategy \& Leadership, 32(5), 23-33.

Norris, E., \& Adam, R. (2017). All Change: Why Britain is so prone to policy reinvention, and what can be done about it. London: Institute for Government. Retrieved from: https://www.instituteforgov ernment.org.uk/sites/default/files/publications/IfG_All_change_report_FINAL.pdf

O'Halloran, K. L. (2008). Systemic functional-multimodal discourse analysis (SF-MDA): Constructing ideational meaning using language and visual imagery. Visual Communication, 7(4), 443-475.

Orlikowski, W. J. (2007). Sociomaterial practices: Exploring technology at work. Organization Studies, 28(9), 1435-1448

Pettigrew, A. (2003). Strategy as process, power and change. In S. Cummings \& D. Wilson (Eds.), Images of strategy (pp. 301-330). London: Wiley-Blackwell.

Rescher, N. (1996). Process metaphysics: An introduction to process philosophy. New York: SUNY Press.

Roth, W. M., \& Bowen, G. M. (2003). When are graphs worth ten thousand words? An expert-expert study. Cognition and Instruction, 21(4), 429-473.

Samra-Fredericks, D. (2000). Doing 'Boards-in-Action' research-an ethnographic approach for the capture and analysis of directors' and senior managers' interactive routines. Corporate Governance: An International Review, 8(3), 244-257.

Samra-Fredericks, D. (2004). Managerial elites making rhetorical and linguistic 'moves' for a moving (emotional) display. Human Relations, 57(9), 1103-1143.

Simons, H. (1996). The paradox of case study. Cambridge Journal of Education, 26(2), 225-240.

Sminia, H. (2009). Process research in strategy formation: Theory, methodology and relevance. International Journal of Management Reviews, 11(1), 97-125.

Smith, W. K., \& Lewis, M. W. (2011). Toward a theory of paradox: A dynamic equilibrium model of organizing. Academy of management Review, 36(2), 381-403.

Stiles, P. (2001). The impact of the board on strategy: An empirical examination. Journal of Management Studies, 38(5), 627-650.

Sundaramurthy, C., \& Lewis, M. (2003). Control and collaboration: Paradoxes of governance. Academy of management review, 28(3), 397-415.

St. Pierre, E. A., \& Jackson, A. Y. (2014). Qualitative data analysis after coding. Qualitative Inquiry, 20(6), 715-719.

Thomas, G. (2011). A typology for the case study in social science following a review of definition, discourse, and structure. Qualitative Inquiry, 17(6), 511-521.

Townley, B. (2014). Bourdieu and organizational theory: A ghostly apparition? In P. Adler, P. du Gay, G. Morgan, \& M. Reed (Eds.), Oxford handbook of sociology, social theory and organization studies: Contemporary currents (pp. 39-63). Oxford: Oxford University Press.

Tricker, B. (2005). Corporate governance-the subject whose time has come. Corporate Governance: An International Review, 8(4), 289-296. 
Watson, C., Husband, G., \& Ireland, A. (2020). Opening the 'black box': What does observational research reveal about processes and practices of governing? Journal of Management and Governance, 26, 1-33.

Whittington, R. (1996). Strategy as practice. Long Range Planning, 29(5), 731-735.

Whittington, R. (2006). Completing the practice turn in strategy research. Organization Studies, 27(5), 613-634.

Whittington, R. (2017). Strategy as practice, process, and institution: Turning towards activity. In A. Langley \& H. Tsoukas (Eds.), The Sage handbook of process organization studies (pp. 387-401). London: Sage Publications Ltd.

Woods, D. K., \& Dempster, P. G. (2011). Tales from the bleeding edge: The qualitative analysis of complex video data using Transana. Forum Qualitative Sozialforschung/Forum: Qualitative Social Research, 12(1), 17.

Publisher's Note Springer Nature remains neutral with regard to jurisdictional claims in published maps and institutional affiliations. 